\title{
A cachoeira do Poço Encantado: empreendimento familiar e presença Kalunga na cadeia do ecoturismo em Teresina de Goiás ${ }^{1}$
}

\author{
Kelma Christina Melo dos Santos Cruz ${ }^{2}$ \\ Ana Lúcia Eduardo Farah Valente ${ }^{3}$
}

Resumo: Apresentam-se os principais resultados e discussões de dissertação de mestrado, cujo objeto é a experiência desenvolvida na Cachoeira do Poço Encantado, no município de Teresina de Goiás, considerando-o, metodologicamente, como manifestação singular da conformação atual da sociedade capitalista, que se apresenta de forma contraditória e dinâmica. Na construção do objeto perseguiram-se os seguintes objetivos: conhecer as estratégias implementadas e que conformam a cadeia do ecoturismo naquela localidade; compreender de que maneira os Kalungas estão inseridos nessa cadeia; refletir sobre a formulação e implementação de políticas públicas que contemplem as comunidades quilombolas no Brasil, e fornecer indicações quanto às perspectivas futuras.

\footnotetext{
${ }^{1}$ Este trabalho baseia-se na dissertação de mestrado da primeira autora, sob a orientação da segunda, apresentada ao Programa de Pós-Graduação Multiinstitucional em Agronegócios do Consórcio Centro-Oeste (UnB/UFMS/UFG). O processo de investigação foi realizado de março de 2003 a dezembro de 2004 e é parte resultante do projeto Desenvolvimento rural em área remanescente de quilombo (Valente, 2003b) que, para sua concretização, recebeu apoio material e financeiro do Conselho Nacional de Desenvolvimento Científico e Tecnológico - CNPq, entidade governamental brasileira promotora do desenvolvimento científico e tecnológico.

${ }^{2}$ Engenheira Agrônoma e Mestre em Agronegócios. kelma@unb.br

${ }^{3}$ Antropóloga, coordenadora do Programa de Pós-graduação em Agronegócios da Universidade de Brasília (UnB) e professora da Faculdade de Agronomia e Medicina Veterinária - FAV/UnB. alefv@uol.com.br
} 
Palavras-chave: Novo Rural; Turismo Rural; Território Quilombola.

Classificação JEL: Q12; R11.

Abstract: The object of study in this research is the ecotourism experience developed in the Poço Encantado Waterfall located in Teresina de Goiás, in the Chapada dos Veadeiros region, Northeast of Goiás. It is a family business established since 1996 opened to public visitation which offers rural and ecological tourism. The activities developed there are also related to the territory of the biggest remaining community of quilombos in Brazil: the Kalunga community. In order to understand this object of study we attempted to attain the following objectives: a) To know the strategies that form and were implemented in the chain of ecotourism in the waterfall of Poço Encantado; b) To understand in what ways the Kalunga people are inserted within such chain; c) To reflect about the formulation and implementation of public policies which can benefit the Quilombolas communities in Brazil; d) To provide a plan concerning future perspectives.

In this research, we chose the single case study as a methodological resource. We consider the Poço Encantado Waterfall to be a unique manifestation that must be contextualized and part of the present capitalist society which presents itself in a contradictory and dynamic way.

The purpose of this research is to contribute in the agribusiness field. This business proposition is to analyze and point out immediate and viable ways to change the approach and strategies in the activities involved along the productive chains.

Keywords: Tourism. Remaining Community of Quilombos.

JEL Classification: Q12; R11.

\section{Introdução}

A Cachoeira do Poço Encantado está localizada a pouco mais de 30 minutos de Alto Paraíso, entrada do Parque Nacional da Chapada dos Veadeiros, no nordeste goiano. É um empreendimento familiar que, em 
1996, foi aberto à visitação, oferecendo turismo rural e ecológico, cachoeiras, rios, lazer e hospedagem. As atividades ali desenvolvidas têm apresentado potencial econômico e vêm se expandindo, por meio da abertura e ampliação do mercado para o artesanato, para produtos tradicionais locais, de cunho cultural, étnico, ecológico e orgânico. Também essas atividades estão relacionadas ao território da maior comunidade remanescente de quilombos do Brasil: a comunidade Kalunga ${ }^{1}$.

Em Teresina de Goiás, o Serviço Brasileiro de Apoio às Micro e Pequenas Empresas (SEBRAE) tem desempenhado um papel importante na indicação das potencialidades turísticas do município, associando-as diretamente à presença dessa comunidade quilombola. Em novembro de 2000, foi realizado pelo Grupo Nativa², em parceria com o SEBRAE/ GO, o Inventário da Oferta Turística de Teresina de Goiás. Segundo os resultados desse trabalho, dos 27 atrativos turísticos da região, o único viável economicamente é a Cachoeira do Poço Encantado. Além disso, o estudo reiterou que o município possui um diferencial em relação às outras localidades da Chapada dos Veadeiros: a presença da Comunidade Kalunga em grande parte do seu território, o que conformaria a identidade turística do município.

Com base em estudo de caso $^{3}$ da experiência desenvolvida na Cachoeira do Poço Encantado, no município de Teresina de Goiás, tivemos por

\footnotetext{
${ }^{1}$ Em 1995, o Governo do Estado de Goiás demarcou o Sítio Histórico e Patrimônio Cultural Kalunga, e em 2000 essa comunidade recebeu do Governo Federal, por meio da Fundação Cultural Palmares (FCP), o Título de Reconhecimento de Domínio sobre a área de 253.191,72 ha.

${ }^{2}$ O Grupo Nativa é uma organização não governamental sediada em Goiânia/GO, com atuação direcionada à proteção, pesquisa e informação ambiental.

${ }^{3}$ Lazzarini (1997) sugere o uso de estudos de caso para pesquisas de fenômenos sociais complexos, nas quais se pressupõe maior nível de detalhamento das relações dentro e entre os indivíduos e organizações, bem como suas interações com o ambiente externo. Godoi (1995b, p. 25) afirma que o objeto do estudo de caso é a análise profunda de uma unidade de estudo e que esse método visa ao exame detalhado de um ambiente, de um sujeito ou de uma situação particular. Por sua vez, Valente (2003a) mostra que o estudo de caso, como técnica, teve procedência na ciência antropológica. Já no primeiro terço do século XX, foram estabelecidas as linhas condutoras da pesquisa antropológica: a exigência do trabalho de campo e o estudo de caso. É característico na produção dos antropólogos o que o peso e a relevância conferidos aos dados empíricos, coletados em exaustivo trabalho de campo, envolvendo a observação etnográfica, o levantamento de dados primários e secundários a partir de diversas fontes e procedimentos técnicos.
} 
objetivos: a) conhecer as estratégias implementadas e que conformam a cadeia do ecoturismo naquela localidade; b) compreender de que maneira os Kalungas estão inseridos nessa cadeia; c) refletir sobre a formulação e implementação de políticas públicas que contemplem as comunidades quilombolas no Brasil e; d) fornecer indicações quanto às perspectivas futuras ${ }^{4}$. Metodologicamente consideramos a Cachoeira do Poço Encantado como manifestação singular da conformação atual da sociedade capitalista, que se apresenta de forma contraditória e dinâmica.

Desde o final da década de 70, os antropólogos vêm se dedicando ao estudo das comunidades negras em situação rural, e as análises do conjunto dos trabalhos produzidos por estes cientistas sociais incidem sobre duas questões específicas: a identidade étnica e a territorialidade. Com base nesses estudos, Valente (2004, p. 516) afirma que a melhoria na qualidade de vida de grupos rurais negros se apresenta como um desafio para a pesquisa no campo do agronegócio. Para a autora:

(...) A situação dessas comunidades impõe que sejam empreendidos esforços para avaliar as possibilidades de inserção econômica de seus membros, a partir da elaboração de projetos de desenvolvimento local sustentável, articulando o conhecimento empírico comunitário e o aporte que poderá ser oferecido por conhecimentos científicos e tecnológicos de apoio à agricultura familiar. Trata-se de temática ainda pouco explorada, mas que pode valer-se das recentes discussões que revisam o conceito de rural, englobando não só as atividades agrícolas como as não agrícolas e que incorporam valores como a dimensão ambiental, a origem territorial, a produção natural e socialmente justa, como atributos capazes de desvelar e agregar valor à produção desses grupos.

Neste momento pretende-se destacar os principais resultados obtidos ao longo da investigação realizada.

\footnotetext{
${ }^{4}$ O ingresso, em março de 2004, no corpo técnico do Programa de Promoção da Igualdade em Gênero, Raça e Etnia, do Ministério do Desenvolvimento Agrário/MDA, possibilitou o acesso a dados importantes, além de favorecer a aproximação contínua com os atores locais. O acompanhamento da última fase das Oficinas Quilombolas (UnB, 2003) permitiu melhor caracterização da Comunidade Kalunga.
} 


\section{Principais resultados}

Na cadeia do ecoturismo em Teresina de Goiás, tomando-se como ponto de partida a Cachoeira do Poço Encantado, destaca-se inicialmente a presença de dois grupos que ocupam posições distintas na estrutura social, que se manifestam no caso singular. De um lado temos a proprietária da Cachoeira do Poço Encantado e do outro a Comunidade Kalunga. Ambos os segmentos fazem parte de um mesmo processo de definição territorial.

O estado de Goiás se constituiu ao final do século XVII, inaugurando um ciclo da mineração que entra em decadência poucos anos depois. A partir desse contexto surgiram as primeiras comunidades quilombolas e certamente famílias proprietárias de escravos por lá ficaram. Assim, as relações entre os dois segmentos possuem raízes históricas inquestionáveis. Ou seja, a Comunidade Kalunga se estrutura de maneira relacional com os antigos senhores de escravos e proprietários dos meios de produção, já que os escravos eram considerados "mercadorias". E vice-versa: os proprietários de escravos têm necessidade da mão-deobra para implementar suas atividades. Em que pesem as fugas para a formação dos quilombos, da resistência das comunidades negras à opressão histórica, essas relações foram mantidas tal como a literatura antropológica especializada no assunto tem indicado.

Não sendo possível falar em isolamento, já que, para garantir sua autonomia, os quilombos sempre mantiveram relações com uma ampla gama de agentes externos, destaca-se a construção da etnicidade. As identidades e os grupos étnicos definem questões de organização social baseadas na auto-atribuição e atribuição por outros a uma categoria étnica. Em geral, estão ligadas a uma situação de desigualdade estrutural que as desencadeia, implicando também um processo de construção de identidades e de fronteiras étnicas (sociais, simbólicas e mutáveis), que permite a diferenciação social e política dos grupos étnicos que estabelecem entre si relações de natureza diversa (Valente, 2004). Significa dizer que a identidade Kalunga apresenta-se firmemente enraizada em território bem delimitado. Em outros termos, a territorialidade negra ou a marca étnica Kalunga na construção do território remonta há mais de três séculos, quando os negros reagem à condição de escravos imposta 
por outra etnia: branca, católica e comprometida com o poder político e econômico ${ }^{5}$.

Por razões históricas, os dois segmentos compartilham o catolicismo, quer na sua vertente "popular", quer na romanizada (Valente, 1994), que promoveu relações de compadrio entre eles, que são, em última análise, relações de poder. Do mesmo modo estabelecem entre si relações trabalhistas. Em decorrência disso, é possível afirmar que entre a proprietária do Poço Encantado e a Comunidade Kalunga existem vínculos do "tipo cola” (coesão comunitária interna) e laços do "tipo ponte” (capacidade de relacionar-se com atores sociais distantes do seu mundo social imediato), ao longo da cadeia do ecoturismo (Abramoway, 2003, p. 71).

Os Kalungas, embora "excluídos" do processo de modernização tecnológica da agricultura, não estão fora das relações capitalistas de produção. Encontram-se na cadeia do ecoturismo, como trabalhadores assalariados, atuando como empregados domésticos, atendentes e recepcionistas em bares, lanchonetes e no Hotel Uirapuru. Também trabalham como guias e prestam serviços de auxílio ao transporte dos turistas. Além disso, produzem tradicionalmente o artesanato e promovem as festas religiosas anualmente.

A proprietária do Poço Encantado exerce forte liderança no local. Faz parte da Pastoral da Criança que além da orientação das mães e acompanhamento do desenvolvimento da criança, distribui um suplemento nutricional, a "multimistura" às gestantes e crianças carentes. Em Teresina de Goiás, sob a coordenação da empresária, nesse trabalho também são oferecidos tratamentos alternativos à base de pomadas, xaropes e chás, agregando o conhecimento tradicional sobre plantas medicinais, partilhado pelos Kalungas e outros munícipes. Esse conhecimento já integra a cadeia, respondendo à demanda dos turistas e produtos com essa marca cultural. São esporadicamente vendidos para Brasília, Cavalcante e Goiânia. Porém, não se configura em prática econômica sistemática, com estratégias que atendam às necessidades de um amplo mercado consumidor.

\footnotetext{
${ }^{5}$ A territorialidade vem ganhando espaço no discurso relacionado à promoção do desenvolvimento rural. Porém diante da diversidade da estrutura agrária brasileira, para a real compreensão desse conceito torna-se fundamental considerar o acúmulo gerado no âmbito das Ciências Sociais, especialmente nos campos da Antropologia, Geografia, Sociologia e Ciência Política.
} 
Recentes levantamentos mostram que o país conseguiu reduzir a mortalidade infantil e grande parte desse resultado deve-se ao trabalho da Pastoral da Criança. Idealizada pela médica Zilda Arns, a Pastoral hoje atende a 36.422 comunidades de 3.555 municípios. Em que pese o envolvimento histórico da Igreja com o poder, a Pastoral da Saúde, muitas vezes coligada às Comunidades Eclesiais de Base ${ }^{6}$, é bastante comprometida com a promoção da igualdade social. A Pastoral da Saúde é um movimento de grande capilaridade e poderia ser um parceiro para a implementação de ações nesse território.

Os Kalungas são agricultores familiares multifuncionais e pluriativos. Combinam múltiplas inserções ocupacionais das pessoas que pertencem a uma mesma família e promovem os cuidados com o território, proteção ao meio ambiente, à salvaguarda do capital cultural, à manutenção de um tecido econômico e social rural pela diversificação de novas atividades ligadas à atividade agrícola. Ao longo de sua história, mantiveram estratégias de segurança alimentar que vêm sendo afetadas diretamente por políticas públicas assistencialistas.

A proprietária da Cachoeira do Poço Encantado é servidora pública federal aposentada e retornou ao seu município de origem para dar continuidade às atividades agropecuárias desenvolvidas há anos por sua família ${ }^{7}$. Em função da sua renda não pode acessar os programas direcionados aos agricultores patronais, podendo ser considerada "pequena entre os grandes". Também não se enquadra nos moldes do PRONAF, mesmo que a gestão do negócio seja familiar. Entretanto, partilha com

\footnotetext{
${ }^{6}$ A Comunidade Eclesial de Base é definida como "uma comunidade local ou ambiental, que corresponde a realidade de um grupo homogêneo e que tenha uma dimensão tal que permita o trato pessoal fraterno entre seus membros (...) célula inicial de estruturação eclesial e foco de evangelização e atualmente fator primordial de promoção humana e desenvolvimento" (Valente, 1994, p. 81). Para a autora esse trabalho resultou na revalorização da religiosidade popular, que passou a ganhar espaço e caracterizar um processo de renovação litúrgica.

${ }^{7}$ Pesquisas recentes orientadas pelo Prof. Dr. Flávio Borges Botelho Filho - FAV/UnB constatam que parte significativa dos avicultores integrados do Distrito Federal iniciaram seus investimentos no setor ao se aposentarem e muitas vezes não possuíam histórico de envolvimento com a atividade agropecuária. Graziano (1997) demonstra que profissionais liberais urbanos, atraídos pelas facilidades decorrentes dos novos serviços disponíveis para apoio das atividades agropecuárias, passaram a olhar os campos como uma oportunidade também para novos negócios.
} 
o público-alvo desse programa muitas características, como a diversificação da produção, os cuidados com o território e proteção ao meio ambiente. Tal como os Kalungas pode ser considerada multifuncional e pluriativa, uma vez que na Fazenda Rio das Pedras desenvolve atividades agropecuárias, e o empreendimento turístico é uma atividade extra. Vale lembrar que atualmente a área da Cachoeira do Poço Encantado é mais valorizada do que toda a Fazenda Rio das Pedras, mas a linha de crédito específica para investimentos no turismo rural, disponível no PRONAF desde 1999, não pode ser acessada.

Freqüentemente as ocupações rurais não-agrícolas são associadas às estratégias específicas de reprodução das explorações familiares. Para Anjos e Caldas (2003), tanto a agricultura a tempo parcial como a pluriatividade emergem como estratégia específica de resistência e adaptação da agricultura familiar diante do impacto de transformações operadas tanto em seu interior como no entorno externo em que esta se acha inserida.

A partir deste estudo de caso, pode-se questionar se os conceitos de multifuncionalidade e pluriatividade são exclusivos desse segmento. Entendemos que a pluriatividade tem incidido principalmente, mas não exclusivamente, nas unidades agrícolas de pequena escala, conforme verificado por Graziano (1997).

Pesquisas associam a pluriatividade à industrialização regional, à indústria doméstica rural, ao turismo ou mesmo à prestação de serviços (Anjos e Caldas, 2003; Schneider, 2004; Graziano, 1997). Dentre essas manifestações, o turismo vem ganhando destaque como atividade econômica e no debate acadêmico.

Diversas tipologias vêm sendo elaboradas com o intuito de classificar as modalidades de turismo. Apesar de, na maior parte das vezes, serem estudos de caso, esses trabalhos são repetitivos, superficiais e não contribuem efetivamente no direcionamento de políticas eficazes. Percebe-se uma tendência a "desumanizar" o turismo, desconsiderando que todo espaço é construído socialmente.

A Cachoeira do Poço Encantado, de acordo com a literatura corrente, configura-se como turismo no espaço rural, por meio do ecoturismo, e turismo rural tradicional e contemporâneo. Compreendendo-se que o turismo não se restringe a uma cadeia produtiva "ideal”, mas a partir da 
relação de atores com diferentes ações e interesses, que se manifestam de forma situacional e dinâmica, apresentamos a seguir a cadeia produtiva gerada a partir do Poço Encantado (Fig.1).

Se, como foi dito, entre os dois segmentos envolvidos na cadeia do turismo em Teresina de Goiás existem vínculos do tipo cola e do tipo ponte, isso não tem sido suficiente para promover o desenvolvimento local, a partir de estratégias que contemplem as características territoriais: é preciso realizar as pontes necessárias, entre os atores locais e entre estes e o ambiente externo e, para isso, é fundamental a existência de políticas públicas específicas. Nessa perspectiva, importa antes de tudo caracterizar esse ambiente externo.

Atualmente, mudanças são operadas no capitalismo e diversos estudos enfocam alterações significativas em curso no meio rural. $\mathrm{O}$ dualismo rural-urbano, responsável pela manutenção e justificativa de desigualdades (Martins, 1986), é definitivamente colocado em xeque. Isso não significa que o rural já não exista mais, mas que passou por profundas transformações. As funções convencionais de fornecimento de matérias-primas e mão-de-obra para o crescimento econômico são cada vez menos importantes, diante dos próprios atributos territoriais que definem, conceitualmente, a ruralidade. Para Abramoway (2003), agricultura, indústria e comércio são setores econômicos. Já a ruralidade é um valor ao qual o mundo contemporâneo atribui cada vez mais importância, por seu significado na preservação da biodiversidade, no fortalecimento de manifestações culturais variadas e por um estilo de vida que os habitantes dos grandes centros buscam cada vez mais.

Teresina de Goiás é considerado um município urbano, com uma população estimada de 2.590 habitantes e a densidade demográfica de 3,34 $\mathrm{hab} / \mathrm{km}^{2}$ (IBGE, 2000). Como se sabe, o IBGE considera urbana toda sede de município (cidade) e de distrito (vila), sejam quais forem suas características. Segundo Veiga (2003), esse modelo gera graves erros, e a constatação da aglomeração como urbana interfere na promoção do desenvolvimento local, visto que a alocação de recursos é diretamente prejudicada. O autor sugere a combinação do critério de tamanho populacional do município com pelo menos outros dois: sua densidade demográfica e sua localização.

Considerando as contribuições do autor, Teresina de Goiás é na verdade um município essencialmente rural. Nessa localidade, existe o pre- 
A cachoeira do Poço Encantado: empreendimento familiar e presença Kalunga na cadeia do ecoturismo em Teresina de Goiás

Figura 1 - Cadeia produtiva do turismo em Teresina de Goiás AMBIENTE INSTITUCIONAL (leis, costumes e tradições)

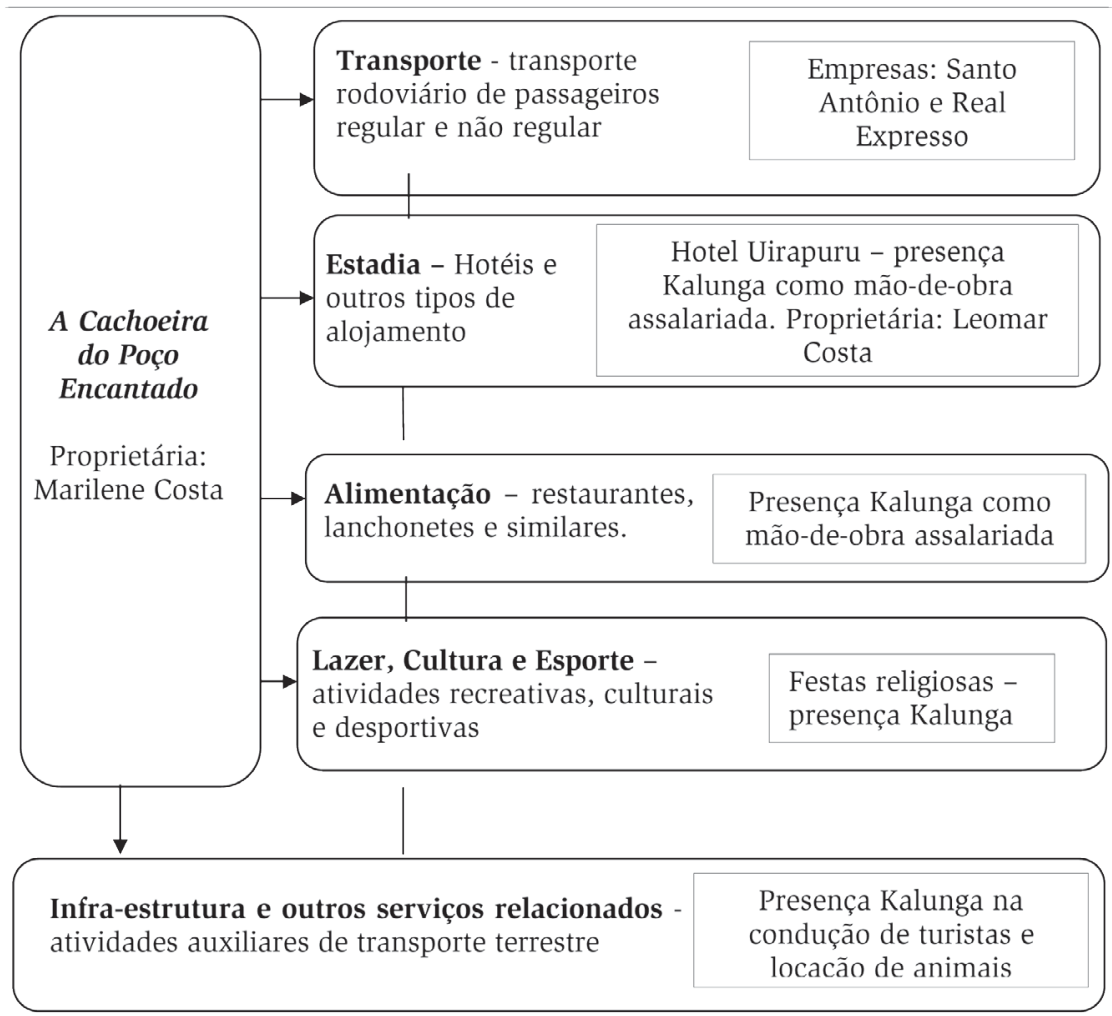

AMBIENTE ORGANIZACIONAL (SEBRAE, AGETUR, UnB, Ministério do Turismo)

Fonte: pesquisa de campo, 2004.

domínio de ecossistemas dos menos artificializados, com belas paisagens naturais, água limpa, ar puro e silêncio. Esse pequeno aglomerado tem a economia vinculada direta ou indiretamente à atividade agropecuária, inclusive o setor secundário e terciário, entre eles o turístico.

Teresina de Goiás apresenta IDH municipal de 0,569 e faz parte de uma das regiões mais pobres do estado. A renda média da população de Teresina de Goiás varia de $\mathrm{R} \$ 50,00$ a $\mathrm{R} \$ 100,00$. Os dados relativos à Comunidade Kalunga apresentam como principais fontes de renda a produção agrícola, os benefícios do INSS, a venda do artesanato e os programas sociais. 
A atividade rural com os membros da mesma família é a principal atividade econômica. Porém as relações tradicionais de produção não atendem as necessidades da população no que diz respeito à ocupação e renda. Por isso, alguns quilombolas trabalham com o artesanato e/ou exercem atividade urbana como empregados domésticos em casas de famílias e pequenos empreendimentos. Essa característica já foi sinalizada por Graziano (2001, p. 16), que considera perverso no Novo Rural o fato de as atividades de prestação de serviços que mais crescem nas áreas rurais serem aquelas ligadas ao trabalho doméstico assalariado. No entender do autor, isso reflete os altos níveis de concentração de renda no país e o baixíssimo nível do salário mínimo vigente.

Alguns quilombolas recebem cestas básicas que eram oferecidas pelo Programa Renda Mínima do Governo Estadual, agora substituído pelo Cartão Alimentação. Além disso, existem beneficiários do INSS, que recebem aposentadoria e pensão por morte, importantes para a manutenção da estrutura financeira familiar (Almeida, 2002).

A situação analisada é semelhante à de vários outros municípios no Brasil. Segundo o IBGE (2004) ${ }^{8}$, quanto menor o município, mais vulnerável é a sua população. Nos municípios que contam com até 5.000 habitantes (o dobro da população de Teresina de Goiás), 37\% das famílias vivem com menos de meio salário mínimo por mês.

Nestes municípios, o número de pessoas sem ocupação é maior. A variação observada pelo IBGE foi de 39,4\%, nos pequenos municípios, a 59,7\%, nos grandes. A quantidade de trabalhadores sem carteira assinada cresce à medida que diminui a população local.

Nos municípios de menor porte populacional, existe a recorrência do analfabetismo funcional ${ }^{9}$, passando de 39,0\% nos municípios com até 5.000 habitantes até $15,6 \%$ nos municípios mais populosos, provavelmente em função da menor oferta de ensino nestas localidades ou, até mesmo, de menores exigências destes mercados de trabalho. Esses municípios oferecem apenas o ensino fundamental, o que obriga o jovem a se deslocar para outra cidade.

\footnotetext{
${ }^{8}$ Indicadores Sociais Municipais - uma análise dos resultados da amostra do Censo Demográfico 2000, realizado pelo Instituto Brasileiro de Geografia e Estatística (IBGE). ${ }^{9}$ Indicador clássico que se refere à proporção de pessoas com menos de quatro anos de estudo completos, considerando que o processo de alfabetização somente se consolida, de fato, entre as pessoas que completaram a $4{ }^{a}$ série do ensino fundamental.
} 
A qualidade de vida nos municípios menores agrava-se pela falta de saneamento básico. Em cidades com até 50 mil habitantes, mais da metade da população vive sem rede de esgoto, fossa séptica e lixo coletado. Na zona rural a situação é ainda pior.

Em todo o Brasil, $27 \%$ das pessoas acima de 60 anos são responsáveis por mais de $90 \%$ do orçamento familiar. Nos municípios com até 20 mil habitantes, $35 \%$ dos idosos contribuem com $30 \%$ a $50 \%$ do rendimento. Nos pequenos municípios, a participação é maior, o que pode ser explicado pelo alto número de aposentados e pensionistas. Em localidades com até 20 mil habitantes, $74,4 \%$ das pessoas com mais de 60 anos são aposentadas, e 8,8\% recebem pensão. Já nas cidades com população acima de 500 mil, a percentagem de aposentados e pensionistas passa, respectivamente, para 59,8\% e 13,9\%.

A maior incidência de aposentados nos municípios menores está provavelmente relacionada à universalização dos benefícios da seguridade social ocorrida durante a década de 1990. Como esses municípios menores se caracterizam fundamentalmente como rurais, os idosos ali residentes puderam se beneficiar do Programa de Assistência ao Trabalhador Rural/Fundo de Assistência e Previdência do Trabalhador Rural (PRORURAL/FUNRURAL), que assistia agricultores, pescadores e garimpeiros (IBGE, 2004).

Para Cazella (2003), a situação de extrema pobreza tem uma correlação com o baixo nível técnico da produção agrícola, inclusive para aquela destinada ao autoconsumo. No que diz respeito aos Kalungas, na região Centro-Oeste confirma-se essa correlação. O exercício de uma agricultura de padrão tecnológico deficiente implica a adoção de outras estratégias econômicas, com destaque para o trabalho externo. O autor estudou situação particular no Sul do Brasil, mas que apresenta o mesmo contexto histórico.

Há uma realidade que extrapola os casos singulares. Teresina de Goiás é um município rural, pobre e com baixos índices de escolaridade. Entretanto, esse perfil é, em geral, associado à presença Kalunga. A eles são destinados "atributos" como preguiça e sujeira, que só se multiplicam pela existência do racismo comprovada nos estudos que fortaleceram a idéia de implementação de políticas de ação afirmativa.

Ao visualizar a cadeia produtiva formada a partir do Poço Encantado, 
fatores como a pouca qualificação da mão-de-obra local e a falta de incentivo governamental para a atividade turística tornam-se indissociáveis do contexto maior em que se inserem.

Embora Teresina de Goiás possua “potencial turístico”, não existe nenhum incentivo no município para o setor. Até a última gestão pública municipal não se acreditava na viabilidade de investir na atividade. A população considera o ecoturismo como a única alternativa de empregos e renda para a região e acredita que qualquer intervenção nesse sentido virá necessariamente “de fora”.

No nível estadual, existem as rotas do turismo elaboradas pela AGETUR, ligada à Secretaria de Planejamento do Estado de Goiás. Junto a essa instituição, Teresina de Goiás aparece como um município em fase de cadastramento, que apresenta pouca infra-estrutura, mas que possui várias potencialidades. Destacam-se o ecoturismo, turismo rural e turismo de aventura ${ }^{10}$. Há, também, sítios arqueológicos e a comunidade dos Kalungas. Foi realizado o Projeto de visitação responsável no sítio histórico-cultural, através das Trilhas Calungas, mas, a partir do diagnóstico, as ações não tiveram continuidade. Efetivamente, na região da Chapada dos Veadeiros, só existem ações da AGETUR em Alto Paraíso e Cavalcante.

No nível federal, existe a pretensão de estimular a atividade turística de forma integrada e regionalizada, orientando a organização do segmento com vistas aos arranjos produtivos e à noção de território a partir do município, passando pelo âmbito estadual. Esse processo envolveria a sociedade civil organizada, o poder público e a iniciativa privada, com ênfase na participação das associações, das cooperativas, dos conselhos de turismo, das instituições de ensino, pesquisa e extensão.

Registramos a presença do SEBRAE em Teresina de Goiás por meio de ações que não tiveram continuidade ${ }^{11}$. A forma de atuação dessa Institui-

\footnotetext{
${ }^{10}$ Existem locais apropriados aos esportes radicais, como rapel, trekking, vôo livre, canoagem, parapente, balonismo, exploração de cavernas, escaladas, rafting, cross country e outros.

${ }^{11}$ Em Teresina foram realizados o Inventário da Oferta Turística (2000) e o Estudo de Potencialidades e Limitações do município (2002). Já em Alto Paraíso - localidade vizinha - o SEBRAE vem implementando a estratégia de arranjos produtivos locais relacionados ao turismo. Embora os dois municípios apresentem interesses conflituosos, Teresina de Goiás possui, além da falta de apoio governamental, a especificidade de ser referência de um território étnico e as implicações que isso envolve, como o preconceito e a discriminação racial no mercado de trabalho.
} 
ção - através da mobilização, disseminação do empreendedorismo e do associativismo gerou expectativas, conflitos e demonstrou-se amplamente incoerente. O SEBRAE, por meio do referencial metodológico do Desenvolvimento Local Integrado e Sustentável (DLIS), propôs a criação do Portal dos Calungas, na entrada da cidade, destacando as riquezas e potencialidades do município, como a arquitetura, o folclore e o patrimônio histórico. Porém, contrariando a valorização do "saber-local", sua primeira recomendação foi um curso de qualificação profissional, em artesanato, desconsiderando o conhecimento das pessoas que há anos praticam essa atividade.

No campo do agronegócio, a valorização do território constitui-se numa importante estratégia para diferenciar a produção e agregar renda às atividades, porém como alcançar tal valorização se torna um desafio. Ao analisar a discussão de linhas temáticas para o apoio à agricultura familiar, promovida pelo CNPq, Valente (2005, p. 8) afirma que "testar processos artesanais de produção" parece um contra-senso, porque "estaria sendo negligenciada a história e a cultura dos produtores, que pode ser conhecida, mas não mensurada a partir de critérios etnocêntricos, que lhes são alheios".

A percepção da comunidade quanto à sua inserção na atividade turística está diretamente relacionada à situação de extrema exclusão social. O problema de capacitação da mão-de-obra local também estabelece relação com o alto índice de analfabetismo da comunidade quilombola e a falta de melhores perspectivas provoca a evasão dos jovens que buscam alternativas em outras cidades.

Para os empreendedores do município, os Kalungas não são qualificados para o trabalho e já não produzem "aquilo que sabiam fazer, como a farinha e o artesanato" devido à implementação de políticas assistencialistas.

Ao considerarmos a percepção dos turistas sobre os Kalungas, vemos que na região pesquisada esta ainda se relaciona à noção de relativo isolamento. Os turistas demonstram interesse em conhecer as práticas "tradicionais" da comunidade, como fica evidenciado durante as festas religiosas. Em Cavalcante/GO, na localidade do Engenho II, diferente do que ocorre em Teresina de Goiás, alguns quilombolas, além de exercerem suas atividades tradicionais de agricultores familiares, também atuam como guias do ecoturismo, tornando-se agricultores por tempo parcial. 
Do ponto de vista político-administrativo, os Kalungas pertencem a diversos municípios (Cavalcante, Monte Alegre e Teresina de Goiás) e essas divisões acabam por definir diferentes territórios além daqueles já existentes. Esta fragmentação se manifesta na implantação das ações que deveriam ser direcionadas à comunidade como um todo. Em razão das divergências entre os prefeitos dos distintos municípios, algumas regiões, por critérios de afinidades políticas, tornam-se privilegiadas.

As políticas públicas que atendem as comunidades quilombolas são recentes e estão em diferentes momentos de implementação. Verificamos que os esforços na sua elaboração não vêm considerando o acúmulo de conhecimento gerado em torno desta questão. Embora o território seja uma construção social, existe a real intenção de artificializá-lo, por meio de intervenções governamentais precipitadas e sem a devida reflexão.

Os principais problemas são basicamente o excesso de burocracia e a desorganização administrativa ou falta de articulação governamental. Existem também interesses políticos conflitantes, tanto no âmbito do governo federal com o estadual quanto do estadual com o municipal (ocorrem conflitos intra e internamente). Há, ainda, problemas de gestão nos diferentes órgãos da esfera federal, configuradas por meio de sobreposições de ações e indecisões quanto às reais competências de cada instituição.

Aqui não pretendemos avaliar a PNATER, PRONAF, Ação Kalunga, Bolsa-Família e Fome Zero, mas sim fornecer alguns indicativos. Até o presente momento, diversas dificuldades foram enfrentadas, mas podem ser feitos alguns redirecionamentos.

Inicialmente o Programa Fome Zero, que era constituído basicamente por ações estruturantes, foi “atropelado" pela exigência de resultados imediatos. A área social - tida como prioritária - passou por reformulações. Nessa nova roupagem, fundiram-se o Ministério da Assistência Social (MAS) e o antigo Ministério Extraordinário de Segurança Alimentar (MESA), sendo criado o atual Ministério do Desenvolvimento Social e Combate à Fome (MDS), responsável pela condução do Programa Fome Zero e pela implementação do Programa Bolsa-Família.

Como beneficiárias do Programa Fome Zero foram escolhidas 150 comunidades quilombolas ou 15 mil famílias, distribuídas em todo o território nacional. A idéia central era promover a auto-sustentabilidade e superação da situação de insegurança alimentar, por meio de ações 
emergenciais e estruturantes. As ações consistiam basicamente em três etapas: a distribuição de alimentos, a realização de oficinas para diagnosticar o perfil socioeconômico e cultural das comunidades e a promoção do acesso aos meios de produção, por meio da entrega de equipamentos para suporte ao desenvolvimento sustentável. Na percepção dos gestores públicos, as duas primeiras etapas foram concluídas e a última se encontra na fase final de execução, mas, até o presente momento, tal intervenção se mostrou inócua.

Apesar da entrega mensal de cestas básicas, na Comunidade Kalunga existe uma situação de insegurança alimentar, nas suas quatro dimensões: quantidade, qualidade, regularidade e dignidade (Valente et al, 2004). Os programas sociais não exigem contrapartida e quando o fazem estas não são acompanhadas/monitoradas, transformando-se em políticas assistencialistas. O Programa Bolsa-Família vem sendo redimensionado, visto que para a sua implementação surgiram graves problemas, a começar pela ineficiência do Cadastro Único, instrumento de acesso ao programa.

As prefeituras contratam agentes de saúde e/ou outros funcionários municipais para realizar o cadastro dos beneficiários, por meio de questionários estruturados. Nesse questionário, na maioria das vezes realizados nas sedes dos municípios, são solicitados os dados cadastrais dos beneficiários. Como as comunidades quilombolas (bem como as indígenas) na imensa maioria das vezes não possuem documentos de identidade, e nem muito menos acesso às áreas urbanas, estas populações não ficam sequer sabendo do processo de cadastramento. $\mathrm{O}$ Cadastro Único é questionado por estabelecer critérios de auto-atribuição e depender das respostas do entrevistador, que "decide" quem vai ou não ser beneficiado.

No âmbito do MDA, a inserção dos quilombolas como público beneficiário é bastante recente, além do fato do próprio Ministério ser bastante novo. Destaca-se a importância do Decreto $n^{0} 4.887$ - que regulamenta o procedimento para identificação, reconhecimento, delimitação, demarcação e titulação das terras ocupadas por remanescentes das comunidades dos quilombos e a formulação da Instrução Normativa $\mathrm{n}^{0} 16$ - que regulamenta dentro do INCRA, os procedimentos para a titulação das terras de quilombo. A questão fundiária é crucial para as 
comunidades quilombolas, mas até o presente momento foram realizadas apenas duas titulações, ambas no estado do Pará, e tanto o Decreto 4.887 quanto a Instrução Normativa $n^{\circ} 16$ precisam ser reformulados.

Em relação ao apoio às atividades produtivas, destaca-se a inclusão dos quilombolas dentro do PRONAF B. Segundo as novas regras, não é necessária a comprovação do título da terra, fator que facilita o acesso ao crédito para esse público. Contudo é preciso destacar que não existe, no âmbito do MDA, um banco de dados sobre o acesso específico dos quilombolas ao crédito rural. As poucas informações disponíveis foram obtidas por meio das Oficinas Quilombolas, promovidas pela FCP, e revelam que do universo das 150 comunidades pesquisadas, 42 acessaram o programa. Observa-se que tais comunidades participam de sindicatos rurais e associações de trabalhadores rurais e não acessaram exclusivamente a modalidade $\mathrm{B}$, mas principalmente a modalidade $\mathrm{D}$, juntamente com produtores rurais "não-quilombolas” da sua região.

Anjos et al (2004), ao analisarem o PRONAF no Rio Grande do Sul, mostraram evidências de diferenciação social dentre os produtores familiares. Nesse estudo, infere-se que a maior dimensão econômica das explorações esteja associada a um maior grau de escolaridade. A condição de alfabetização indica a presença de um “filtro” no acesso ao PRONAF e mecanismos de ascensão social. Isso fica evidente ao constatar que o rendimento médio dos pronafianos do subgrupo D é 3,7 vezes maior que os do subgrupo B e 3,2 vezes maior em termos de renda mediana.

Também evidencia que a participação mais baixa do trabalho agrícola dá-se no subgrupo B dos pronafianos, alcançando 35,6\% da renda total domiciliar anual. Parece lógico supor que se trata de estabelecimentos mais frágeis do ponto de vista das condições materiais em que operam os produtores, havendo cerca de 1/3 de participação de outras fontes, como ajudas governamentais, e contribuição do autoconsumo. Finalmente, o estudo revelou que na região pesquisada nenhum quilombola acessa o programa.

Conforme os autores identificaram, as dificuldades do PRONAF são inúmeras, não só no modo de fomentar este amplo e diversificado segmento da agricultura brasileira, quanto na eleição do público-alvo a ser beneficiado (Anjos et al , 2004, p. 531). Baseado em Veiga e Abramoway (1998), os autores consideram que o conceito proposto na operaciona- 
lização do PRONAF parece mais ser "o resultado de uma negociação política” do que uma definição precisa e minimamente lógica, visto que se trata de um universo social extremamente diversificado e não menos contraditório em sua composição. Acrescentam ainda que este programa claramente identifica o verdadeiro agricultor como aquele produtor apoiado, quase que exclusivamente, na exploração agropecuária de uma unidade de produção e consideram ser este um grave erro, visto que agricultores em geral formarão parte de um número cada vez mais reduzido de pessoas residentes no meio rural (Anjos et al , 2004, p. 546).

Em julho de 2004, na última seleção de projetos do PRONAF Capacitação, foi pela primeira vez inserida no edital uma linha específica para o Etnodesenvolvimento. O MDA apresentou como exigência às entidades proponentes, na maioria das vezes ONG's, a anuência das comunidades às quais os projetos seriam destinados. Este procedimento mostrou-se ineficiente por desconsiderar o analfabetismo, a falta de informação e a suscetibilidade à manipulação política ${ }^{12}$, o que significa dizer que as comunidades quilombolas não estão "empoderadas” para acessar as políticas públicas.

As políticas públicas atendem às pressões dos grupos de interesse e apenas recentemente incorporam as demandas apontadas por diversos estudiosos e Movimento Negro. Nacionalmente existe o Conselho Nacional de Quilombos (CONAQ), que reúne representações de todo o Brasil. Paralelamente, porém, em estados como o Pará - onde a luta pela terra ocasionou o surgimento de associações e entidades estaduais de representação, como a MALUNGU - existem ações paralelas e independentes à atuação da CONAQ. O próprio Movimento Negro reivindica a "paternidade” da luta das comunidades quilombolas, mas existem divergências próprias ao processo de emancipação desses grupos.

Aos Kalungas foi conferida bastante visibilidade, na mídia, mas possuem pouca representatividade e uma incipiente prática organizativa. A Ação Kalunga, coordenada pela SEPPIR, está em fase de implementação, mas notoriamente falta o controle social, o monitoramento e a avaliação.

No Conselho Nacional de Desenvolvimento Rural Sustentável (CON-

${ }^{12}$ França (2003) apresenta os eventos que trouxeram a Comunidade Kalunga para o campo da interlocução desenhado pelo Estado nos últimos vinte anos e propõe uma reflexão sobre os impactos do momento atual na subjetivação dos membros do grupo e nas suas opções políticas internas. 
DRAF), foi instituído um comitê permanente de Promoção da Igualdade de Gênero, Raça e Etnia. A idéia central é fomentar e fortalecer a participação dos quilombolas nas instâncias locais de decisão. Em Teresina de Goiás existe o Conselho Municipal de Desenvolvimento Rural (CMDR), mas não ocorre a participação efetiva de representantes de diversos segmentos, não havendo com isso mudanças no ambiente institucional. As resoluções do Conselho vêm se concentrando nas questões da produção agrícola e da infra-estrutura básica do meio rural.

O MDA lançou também o Programa Nacional de Turismo Rural na Agricultura Familiar. Este programa oferece instrumentos como crédito para investimento, capacitação, assistência técnica e extensão rural. Para a implantação do programa, o MDA conta com o apoio da Rede de Turismo Rural na Agricultura Familiar (Rede TRAF) para os beneficiários do PRONAF, incluindo os quilombolas.

Embora o território Kalunga se encontre numa zona com alto potencial turístico, nenhuma ação foi direcionada nesse sentido. Não se trata aqui de defender "o turismo", mas sim considerar o que já existe no território, a dinâmica local. Ao invés de oferecer cursos de qualificação para o artesanato, proposta do SEBRAE, parece mais apropriado promover o "desvelamento do valor" (Valente, 2005) das atividades ali realizadas, por meio da valorização e legitimação do que é produzido.

Na gestão das ações direcionadas às comunidades quilombolas, é evidente o desconhecimento da realidade desses grupos. Freqüentemente são elaborados critérios duvidosos para a tomada de decisão. Problemas na gestão ficam evidentes, denotando duas características principais: um militantismo infantil ${ }^{13}$ e a satanização dos segmentos "mais capitalizados". Esses erros levam à desconsideração da desigualdade flagrante entre os segmentos e à exclusão dos que possuem

\footnotetext{
${ }^{13}$ Valente (1995, p. 146) acredita que talvez por um envolvimento exagerado dos pesquisadores com a questão negra, por ingenuidade teórica e, certamente, pela falta de percepção das diferenças entre o cientista e o político, os conceitos analíticos da militância e mesmo os conceitos pessoais incorporaram-se às análises. Para a autora, isto dificultou a distinção dos fatos observados, objetos da reflexão científica, com as impressões e desejos desses pesquisadores. Muitos também se deixaram levar por uma "ditadura intelectual" imposta pela militância negra que negava valor a qualquer interpretação distante da sua.
} 
vínculos com ações de maior capilaridade, diferentemente das ONG's ${ }^{14}$ a quem sempre se recorre.

Em Teresina de Goiás, para implementação da Ação Kalunga, foram realizados vários eventos com lideranças Kalungas, visando sempre o seu "protagonismo". Porém, não foram promovidas as pontes necessárias, visto que a comunidade não vive isolada. Exemplo disso é que a proprietária do Poço Encantado nunca foi procurada por nenhum órgão federal, ou estadual, com propostas que viabilizassem a participação dos Kalungas na cadeia do ecoturismo como parceiros potenciais. Vale destacar que a desigualdade estrutural ali existente coloca em xeque a concepção de parceria entre iguais.

Assim, na cadeia do ecoturismo em Teresina de Goiás, as ações muitas vezes incoerentes das entidades que compõem o ambiente organizacional e a desconsideração ou negligência no ambiente institucional dos costumes e tradições locais tendem a dificultar a implementação de estratégias de desenvolvimento local. Neste contexto, compromete-se a discussão da sustentabilidade.

Se levarmos em consideração o modelo de Egler (2001), percebe-se que existem problemas na formulação e implementação das políticas públicas. Atualmente este processo não apresenta uma lógica e, conseqüentemente, não atinge seus objetivos. Finalizando, o discurso que vem sendo construído pelos gestores das políticas públicas, de promoção do desenvolvimento territorial, de respeito à lógica e conhecimentos locais, tem se mostrado, na prática, incoerente, se não falacioso.

\section{Considerações finais}

Esta pesquisa se inscreveu no exato momento da "construção social", quando antigos movimentos ganham visibilidade e diferentes processos se articulam. Nela está implícita a dificuldade de análise, já que a reflexão

\footnotetext{
${ }^{14}$ Para Valente (2000), as ONG's e entidades da sociedade civil do mesmo molde dispõem de uma certa margem de liberdade de reflexão e atuação, sem as habituais pressões e imposições dos setores governamentais. No entanto, mesmo que proclamem a sua independência ante os organismos nacionais e internacionais, existe uma real necessidade de recursos financeiros que viabilizem seu funcionamento, por meio da aprovação de projetos que devem percorrer os processos de avaliação, definidos fora de sua esfera de autonomia (Valente, 2000, p. 121).
} 
reclama por pontos firmes sobre os quais possa se estruturar. Entretanto, nessa dificuldade reside o desafio explícito no campo do agronegócio que se propõe, para, além da análise, indicar caminhos possíveis e imediatos para mudança de enfoques e estratégias nas atividades envolvidas ao longo de cadeias.

São caminhos possíveis:

1) A produção teórica relacionada ao turismo rural não contempla a diversidade da estrutura agrária brasileira e está repleta de generalizações, concentrando-se no aprofundamento do conceito e na elaboração de tipologias. Para contribuir efetivamente, as pesquisas devem fornecer indicações quanto às estratégias e dinâmicas próprias dos territórios, assumindo que estes são construídos socialmente e possuem outras especificidades além da delimitação geográfica.

2) Teresina de Goiás apresenta elevado grau de debilidade econômica - baixos índices de escolaridade e grave situação de pobreza - e, em decorrência desse perfil, o turismo rural se converte em alternativa de emprego e renda no município. Para a promoção do desenvolvimento local, é prioritário investir em saúde, viabilizando o atendimento médico-hospitalar, e educação, garantindo a alfabetização da população, por meio, por exemplo, da Escola Família Agrícola (EFA) e da formação de professores.

3) Teresina de Goiás é um município “rural”, com o predomínio de ecossistema natural e grande diversidade biológica, mas tais atributos não vêm sendo valorizados pelos gestores públicos. Deve-se incorporar essa dimensão à Ação Kalunga. Atrativos naturais podem captar rendas urbanas e a promoção da diversidade biológica poderá ser um fator crucial na dinamização das regiões rurais, incentivando simultaneamente a conservação da biodiversidade e a criação de empregos (Veiga, 2001).

4) No Conselho Municipal de Desenvolvimento Rural, em Teresina de Goiás, não estão representados os proprietários rurais mais capitalizados e os empreendedores ligados a outros setores da economia. Em decorrência disso, não ocorrem mudanças no ambiente institucional. Para a promoção do desenvolvimento rural, é preciso que o CONDRAF realize uma eficaz concertação (concentração?????) entre todos os segmentos envolvidos na dinâmica local, viabilizando um entendimento entre as lideranças, para investimentos nas atividades que permitam sinergias, incluindo as atividades não-agrícolas. 
5) As intervenções públicas não alcançaram resultados efetivos na localidade estudada e têm acirrado a disputa entre as regiões administrativas e os conflitos entre a população. Seguindo a indicação de Veiga (2001), propõe-se um contrato territorial de desenvolvimento (CTD) a ser firmado por meio de articulações intermunicipais reunindo Cavalcante, Teresina e Monte Alegre, garantindo a coerência do território Kalunga. Cavalcante teria maiores condições de "alavancar" esse grupo, no sentido de potencializar a habilidade das prefeituras para utilização dos programas sociais, planejar ações de desenvolvimento integrado e captar os recursos necessários à sua execução.

6) A cadeia do ecoturismo em Teresina de Goiás é formada a partir de relações construídas historicamente e por isso marcada pela contradição e conflito. Deparamo-nos com dois segmentos que há muito tempo estabelecem relações de parceria, submissão e competição. Propõe-se a elaboração e implementação de políticas públicas "intermediárias” para os grupos envolvidos, visto que as intervenções no âmbito dessa cadeia não serão realizadas entre iguais e as ações governamentais não podem desconsiderar isso.

7) No campo do agronegócio, incorporar aspectos territoriais aos produtos, transformando atributos culturais em valor econômico, é um desafio. A experiência internacional tem mostrado que a certificação de produtos de origem é um processo de construção que tem início a partir da valorização do que é tradicionalmente produzido em determinada região. No caso estudado, fazemos referência ao "desvelamento de valor”, por meio da valorização do processo de trabalho concreto, como manifestação da cultura (Valente, 2005). A partir das potencialidades territoriais e do reconhecimento das habilidades e competências da comunidade Kalunga, deve-se "desvelar valor" e potencializar sua condição de parceiros na cadeia do ecoturismo.

8) A Ação Kalunga, coordenada pela SEPPIR, gerou muitas expectativas, conflitos e desgaste na Comunidade Kalunga. Deve-se buscar caminhos alternativos no sentido da articulação governamental e desburocratização. A questão fundiária é crucial para a população Kalunga e, embora o processo seja lento e demorado, é prioritário que o INCRA garanta a propriedade da terra como forma de legitimar os direitos da comunidade.

9) A Política Nacional de Assistência Técnica e Extensão Rural 
- PNATER (Brasil, 2004) apresenta como eixos fundamentais o respeito à pluralidade e às diversidades sociais, econômicas, étnicas, culturais e ambientais do país. No sentido de potencializar atividades produtivas agrícolas voltadas à oferta de alimentos, bem como apoiar estratégias de comercialização e agroindustrialização, é preciso assegurar à comunidade Kalunga serviços de ATER continuada.

10) As políticas públicas direcionadas às comunidades quilombolas são recentes e estão em diferentes momentos de implementação. Em que pese o acúmulo de conhecimento produzido no campo antropológico, nos órgãos responsáveis pela sua formulação existe desconhecimento do real universo a ser contemplado e de suas características. Para suprir essa necessidade, propõe-se a realização de convênios com entidades de pesquisa, universidades e a Associação Brasileira de Antropologia (ABA), para aquisição de relatórios simplificados relativos aos trabalhos já desenvolvidos junto a esses grupos.

A partir destes dez pontos listados, é previsível que inúmeros desdobramentos possam ser imaginados. No entanto, interessa nestas considerações finais apenas destacar, em termos operacionais, o que procuramos sinalizar ao longo da dissertação de mestrado. Nela esperamos ter oferecido uma contribuição ao campo do agronegócio, refletindo sobre um contexto complexo que envolve um dos segmentos mais empobrecidos da população brasileira: as comunidades negras rurais. Muito pouco tem sido feito para atender as suas demandas. Isso porque é preciso, para além das "boas intenções”, sustentar qualquer ação sobre bases teóricas e práticas mais sólidas, um desafio para aqueles que estão dentro e fora da Academia.

\section{Referências bibliográficas}

ABRAMOVAY, Ricardo. O futuro das regiões rurais. Porto Alegre: Editora da UFRGS, 2003.

ANJOS, F. C.; CALDAS, N. V. Pluriatividade e Ruralidade: falsas premissas e falsos dilemas. III Seminário Novo Rural Brasileiro. A dinâmica das atividades agrícolas e não agrícolas no Novo Rural Brasileiro Fase III do Projeto Rurbano. Campinas, NEA - Instituto de Economia/ UNICAMP, 3 e 4 de julho de 2003. 
ANJOS, F. S.; GODOY, W. I.; CALDAS, N. V.; GOMES, M. C. Agricultura Familiar e Políticas Públicas: o Impacto do Pronaf no Rio Grande do Sul. Rev. Econ. Sociol. Rural. Brasília, Vol 42, N 03, p. 529 a 548, Jul/Set de 2004.

ALMEIDA, A. N. Determinantes do consumo de famílias com idosos e sem idosos com base na pesquisa de orçamentos familiares 1995/96. Universidade de São Paulo, 2002.

BRASIL. IBGE, Instituto Brasileiro de Geografia e Estatística. Indicadores Sociais Municipais: Uma análise dos resultados da amostra do Censo Demográfico de 2000 - Brasil e grandes regiões. Série Estudos e Pesquisas - Informação Demográfica e socioeconômica, $\mathrm{n}^{0} 14$. Rio de Janeiro, 2004.

BRASIL. Ministério do Desenvolvimento Agrário. Plano safra - 2004/2005. (Cartilha informativa).

CAZELLA, A. A. A multifuncionalidade agrícola numa zona rural "desfavorecida”: um estudo de caso na região serrana catarinense. In: CARNEIRO, M. J.; MALUF, R. S. (orgs.)Para além da produção: multifuncionalidade e agricultura familiar. Rio de Janeiro: MAUAD, 2003. 230 p.

EGLER, P. C. G. Políticas Públicas: Marcos Conceituais e Processos. PósGraduação do Centro de Desenvolvimento Sustentável da UnB. Notas de aula. Brasília: CDS/UnB. $1^{\circ}$ semestre de 2001. (mimeo).

FRANÇA, D. J. A Comunidade Kalunga e a Interpelação do Estado: da invisibilidade à identidade política. Departamento de Antropologia. Universidade de Brasília, 2003.

GODOI, A. Introdução à pesquisa qualitativa e suas possibilidades, In Revista de Administração de Empresas, v. 35, n. 2, Mar./Abr. 1995a, p. 57-63.

GRAZIANO DA SILVA, J. O novo rural brasileiro. Nova Economia, Belo Horizonte, v.7, n.1, p. 43-81, 1997.

GRAZIANO DA SILVA, J. Quem precisa de uma estratégia de desenvolvimento. Brasília: Ministério do Desenvolvimento Agrário/ Conselho Nacional de Desenvolvimento Rural Sustentável/ Núcleo de Estudos Agrários e Desenvolvimento Rural, 2001. 
LAZZARINI, S. G. Estudos de Caso para fins de pesquisa: aplicabilidade e limitações do método. In: FARINA, E. Et al. (Coord.) Estudos de Caso em Agrobusiness. São Paulo: Pioneira/PENSA, 1997. p. 9-23.

MARTINS, J. S. As Coisas no Lugar (Da ambigüidade à dualidade na reflexão sociológica sobre a relação cidade-campo). In: Martins (org.). Introdução crítica à Sociologia Rural. 2 ed. São Paulo: Hucitec, 1986.

SCHNEIDER, S. Agricultura familiar e industrialização: pluriatividade e descentralização industrial no Rio Grande do Sul/ Sérgio Schneider.(Série Estudos Rurais). 2. ed., Porto Alegre: Editora da UFRGS, 2004.

SEBRAE. Inventário e diagnóstico turístico do município de Teresina de Goiás. PRODER/GRUPO NATIVA/ PROGRAMA SEBRAE DE TURISMO, Goiânia, 2000.

Estudo das potencialidades e limitações do município de Teresina de Goiás (GO). MPN Consultoria, Marketing e Negócios/ PROGRAMA CAMINHOS PARA O DESENVOLVIMENTO SUSTENTÁVEL DE GOIÁS/SEBRAE, Goiânia, 2002.

UNIVERSIDADE DE BRASÍLIA. Comunidades Quilombolas: levantamento sócio-econômico cultural. Relatório estatístico quantitativo e qualitativo das oficinas. MDS/MDA/SEPPIR/ FCP (coordenadores). Versão preliminar publicada em 2004.

VALENTE, A. L. E. F. O negro e a Igreja Católica: o espaço concedido, um espaço reivindicado. Campo Grande, CECITEC, 1994.

VALENTE, A. L. E. F. Repensando a questão da territorialidade negra. Afro-Ásia. Publicação do Centro de Estudos Afro-Orientais (CEAO) da Universidade Federal da Bahia em co-edição com a EDUFBA, ${ }^{\circ}{ }^{0}$, 1995, p. 133-147.

Estado, educação e etnicidade: a experiência Belga. Cadernos de Pesquisa, n ${ }^{0}$ 105, Fundação Carlos Chagas, nov. 1998, p.135-159.

Educação na Bélgica e tendências globais: os novos braços do Estado seriam as ONG's? FERREIRA.; GUGLIANO (orgs)_Fragmentos da globalização na educação: uma perspectiva comparada. Porto Alegre: Artes Médicas Sul, pp. 111-127, 2000. 
Reflexões sobre o estudo de caso: subsídio à pesquisa no campo do agronegócio, 2003a (texto digitado).

Desenvolvimento rural em área remanescente de quilombo. Projeto aprovado no Edital MCT/MESA/CNPq/ CT Agronegócio 01/2003b.

Agricultura familiar e recorte racial: desafio teórico e sóciopolítico no meio rural. XLII Congresso da SOBER, 2004.

Desvelar valor: contribuição conceitual ao agronegócio, 2005 (digitado).

VALENTE, A. L. E. F.;SOUZA, M. L. G.; SILVA, C. M. V.; GIORDANO, R. N. E.; MAROCLO, A. C. Dimensão quantitativa da Segurança Alimentar em território Kalunga. $1^{\circ}$ Congresso Brasileiro de Gastronomia e Segurança Alimentar. Brasília, 2004.

VALENTE, A. L. E. F.; SILVA, C. M. V.; SOUZA, M. L. G.; GIORDANO, R. N. E. Qualidade da Segurança Alimentar em território Kalunga. $1^{\circ}$ Congresso Brasileiro de Gastronomia e Segurança Alimentar. Brasília, 2004.

VALENTE, A. L. E. F.; GIORDANO, R. N. E.; SILVA, C. M. V; SOUZA, M. L. G.; MAROCLO, A. C. Regularidade e Dignidade da Segurança Alimentar em território Kalunga. $1^{\circ}$ Congresso Brasileiro de Gastronomia e Segurança Alimentar. Brasília, 2004.

VEIGA, J. E. O Brasil rural ainda não encontrou seu eixo de desenvolvimento. Revista Estudos Avançados 15(43), 2001, pp. 101-119.

VEIGA, J. E. Cidades imaginárias. Campinas: Autores associados, 2002. pp. 31-52.

VEIGA, J. E.; ABRAMOWAY, R. Novas Instituições para o Desenvolvimento Rural: o caso do Programa Nacional de Fortalecimento da Agricultura Familiar - PRONAF. Série: Textos para a Discussão, nº 641, abril de 1998.

Recebido em maio de 2005 e revisto em novembro de 2005 